\title{
Spotlight on nivolumab in the treatment of renal cell carcinoma: design, development, and place in therapy
}

\author{
This article was published in the following Dove Press journal: \\ Drug Design, Development and Therapy \\ II April 2017 \\ Number of times this article has been viewed
}

\author{
Vyshak Alva Venur' \\ Monika Joshi \\ Kenneth G Nepple ${ }^{3}$ \\ Yousef Zakharia' \\ 'Division of Hematology Oncology \\ and Bone Marrow Transplant, \\ Department of Internal Medicine, \\ University of lowa Hospitals and \\ Clinics, lowa City, IA, ${ }^{2}$ Division of \\ Hematology-Oncology, Penn State \\ Cancer Institute, Hershey, PA, \\ ${ }^{3}$ Department of Urology, University \\ of lowa Hospitals and Clinics, lowa \\ City, IA, USA
}

\begin{abstract}
Several tyrosine kinase inhibitors targeting the vascular endothelial growth factor receptors and molecules inhibiting the mammalian target of rapamycin are being used for management of metastatic renal cell carcinoma ( $\mathrm{mRCC}$ ); however, there is still a potential for improvement. Immune checkpoint inhibitors like nivolumab and other PD-1/PD-L1 inhibitors provide an alternative approach for patients with mRCC. In this article, the authors review the safety profile and outcomes of phase 1, 2, and 3 clinical trials of nivolumab in mRCC.
\end{abstract}

Keywords: renal cell carcinoma, kidney cancer, PD-1, nivolumab, immunotherapy

\section{Introduction}

Renal cell carcinoma (RCC) is the eight most common cause of cancer in the United States with an estimated 62,700 new cases in 2016. ${ }^{1}$ Histologically, the majority of $\mathrm{RCC}$ is classified as clear cell $(75 \%-85 \%)$. Non-clear cell RCC include papillary $(10 \%-15 \%)$ and chromophobe $(4 \%-5 \%)$ in addition to other rare forms such as renal medullary cancer. ${ }^{2}$ Approximately two-thirds (65\%) of kidney cancers are diagnosed in early stages, and surgery with partial or radical nephrectomy is the treatment of choice. However, up to $30 \%$ of patients who have up-front surgery eventually develop local recurrence or metastatic disease. ${ }^{3,4}$ Another $35 \%$ of all RCC are diagnosed at advanced stage. Cytoreductive nephrectomy plays a significant role in the management of a subgroup of metastatic RCC (mRCC). ${ }^{5}$ Traditional chemotherapy has shown no clinical activity in $\mathrm{mRCC}$ except for patients with renal medullary cancer. Interferon- $\alpha(\mathrm{INF} \alpha)$ and interleukin-2 (IL-2) had been the mainstay of treatment. ${ }^{6}$ These agents produce complete responses (CRs) in a small percentage of patients but have significant adverse effects. ${ }^{7}$ Since 2005, several tyrosine kinase inhibitors (TKI) targeting the vascular endothelial growth factor (VEGF) receptors and inhibitors of the mammalian target of rapamycin (mTOR) have been approved for the management of mRCC. Sunitinib, pazopanib, temsirolimus, and bevacizumab (in combination with INF $\alpha$ ) are approved in the first-line setting, whereas sorafenib, cabozantinib, axitinib, and everolimus (as a single agent or in combination with lenvatinib) are approved as second-line agents. ${ }^{8-13}$

Several observations over the years have shown that $\mathrm{RCC}$ is an immune responsive tumor, for example, nephrectomy in $\mathrm{mRCC}$ has been shown to occasionally cause resolution of metastatic lesions in the lung, which was noted to occur with autoimmune flair in several cases. ${ }^{14,15}$ Also, mRCC responds to INF $\alpha$ and IL-2 both of which are classic immune-based therapies. An objective response rate (ORR) of 10\%-19\%,
Division of Bone Marrow Transplant, Department of Internal Medicine, 200 Hawkins Drive, University of lowa Hospitals and Clinics, lowa City, IA, 52242, USA

$\mathrm{Tel}+\mathrm{I} 3193841616$

Fax +I 3193538383

Email yousef-zakharia@uiowa.edu

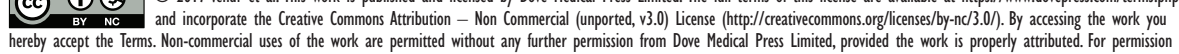
for commercial use of this work, please see paragraphs 4.2 and 5 of our Terms (https://www.dovepress.com/terms.php).
her 
with durable CRs in 5\%-8\% of patients, was demonstrated with IL-2. ${ }^{16}$ In addition, cytoreductive nephrectomy prior to INF $\alpha$ therapy had a better outcome compared to INF $\alpha$ alone, which could be partly based on amplification of immune response by the surgery. ${ }^{5}$ Therefore, when the new generation of immune-based therapies were being tested, RCC was an obvious choice.

\section{Mechanism of action and pharmacology}

Nivolumab is a fully human, genetically engineered monoclonal IgG4 antibody specific for the programmed death-1 (PD-1) cell surface receptor. Pembrolizumab is another monoclonal antibody against PD-1, which is approved for the management of metastatic melanoma and metastatic non-small-cell lung cancer. The interaction between tumor cells and the immune system is complex with several on and off switches that prompt stimulation or inhibition. Antigen presenting cell via major histocompatibility complex-1 interact with the T-cell receptors on the T cells. During this interaction, several co-stimulatory and co-inhibitory surface receptors, also known as immune checkpoints, determine whether the T cells get activated or not. ${ }^{17} \mathrm{PD}-1$, cytotoxic T-lymphocyteassociated protein 4 (CTLA-4), and TIM-3 are some of the known inhibitory receptors, whereas OX-40, CD-27, and GITR are some of the known co-stimulatory receptors on the T cells. ${ }^{18}$ The ligand for PD-1, PD-L1, is expressed on normal cells including placenta, macrophages, and dendritic and endothelial cells. ${ }^{19,20}$ It is also expressed in various tumors, including melanoma, non-small-cell lung cancer, and RCC among others. ${ }^{21}$ The interaction between PD-1 and PD-L1 leads to T-cell exhaustion and immune tolerance. ${ }^{22}$

Preclinical data regarding the importance of PD-1/PD-L1 in downregulating immune response comes from studies in mice. ${ }^{23}$ A null mutation in the PD-1 genes of transgenic mice leads to chronic and systemic graft-versus-host disease. ${ }^{23}$ Mice models with the knockout of PD-L1 develop lupuslike arthritis and glomerulonephritis with IgG3 immune deposition.

Nivolumab is administered intravenously and is currently available in $40 \mathrm{mg} / 4 \mathrm{~mL}$ or $100 \mathrm{mg} / 10 \mathrm{~mL}$ vials. Linear pharmacokinetics was noted in phase 1 clinical trials with dose-proportional increase in the peak concentration and area under the curve calculated from day 1 to $14 .^{24}$ The peak concentration is achieved within 1-4 hours after the start of infusion. Age (29-87 years), weight (35-160 kg), gender, race, baseline $\mathrm{LDH}$, renal impairment, and mild hepatic impairment did not affect the clearance of nivolumab. ${ }^{25}$

\section{Phase I clinical trial}

The initial dose finding clinical trial of nivolumab enrolled heavily pretreated patients (median of four prior lines of therapy) with progressive advanced RCC, metastatic melanoma, non-small-cell lung cancer, colorectal, and castrate-resistant prostate cancer. ${ }^{26}$ Sequential cohorts of six patients were treated with four different doses of $0.3,1,3$, or $10 \mathrm{mg} / \mathrm{kg}$ with each infusion lasting 60 minutes. Fifteen additional patients were planned to receive the maximum tolerated dose (MTD) or $10 \mathrm{mg} / \mathrm{kg}$ (the highest planned dose). Weekly evaluation for toxicity was performed for a total of 8 weeks. Adverse effects of grade 3 or greater in severity or laboratory abnormality corresponding to grade 3 or greater occurring within 28 days was considered doselimiting toxicity. A total of 39 patients were treated, which included 6 each at $0.3,1$, and $3 \mathrm{mg} / \mathrm{kg}$ dose, and 21 patients received $10 \mathrm{mg} / \mathrm{kg}$. Overall, nivolumab was well tolerated and the MTD was not reached. Most frequent grade 2 or greater adverse events were decrease in CD4 lymphocyte count (35.9\%), lymphopenia (25.6\%), fatigue (15.4\%), and musculoskeletal events (15.4\%). Specifically, no grade 3 or greater immune-related adverse effects were reported within 28 days of the first dose. Two patients were reported to have grade 2 polyarticular arthropathy, which improved with steroids, and one patient had grade 2 hypothyroidism, which was treated with hormone supplementation. Only one patient developed grade 3 colitis after five infusions of nivolumab at $1 \mathrm{mg} / \mathrm{kg}$. This colitis was noted 8 months after the first dose and was treated successfully with infliximab. One patient with colorectal cancer who was treated with nivolumab at $3 \mathrm{mg} / \mathrm{kg}$ had CR, two patients had partial response, and two had mixed response with regression in some lesions and progression in others.

Safety and tolerability were evaluated in another expanded phase 1 trial. ${ }^{24}$ This trial had a similar dose escalation strategy in similar recurrent or progressive malignancies as the previous one. Patients were sequentially enrolled to receive nivolumab at 1,3 , or $10 \mathrm{mg} / \mathrm{kg}$ of body weight. No MTD was encountered. Further patients were enrolled in the two stages of cohort expansion. Initially, five cohorts of $\sim 16$ patients each were enrolled at doses of $10 \mathrm{mg} / \mathrm{kg}$ for melanoma, non-small-cell lung cancer, RCC, castrationresistant prostate cancer, and colorectal cancer, and based on the preliminary activity signals, 16 patients were enrolled additionally in three more cohorts of melanoma, non-smallcell lung cancer, and RCC. The study finally accrued 104 melanoma, 122 non-small-cell lung cancer, 34 RCC, 19 colorectal, and 17 castrate-resistant prostate cancer patients 
for a total cohort of 296 patients. Among the 34 RCC patients, 32 (94\%) had prior nephrectomy, 10 (29\%) had more than four lines of prior systemic therapies, and notably 20 (59\%) had prior immunotherapy. Nivolumab was well tolerated with fatigue, rash, diarrhea, nausea, pruritus, decreased appetite, pyrexia, and headache being the most common drug-related adverse effects. Potential less frequent immune-related adverse events including pneumonitis, colitis, hepatitis, hypophysitis, thyroiditis, and vitiligo were reported in this study. Objective responses were noted in non-small-cell lung cancer, melanoma, and RCC patients. Among the 34 RCC patients, nivolumab was dosed at $1 \mathrm{mg} / \mathrm{kg}$ in 18 patients and $10 \mathrm{mg} / \mathrm{kg}$ in the remaining 16 patients. Four of the 18 patients $(24 \%)$ receiving $1 \mathrm{mg} / \mathrm{kg}$ and 5 of the 16 patients (31\%) receiving $10 \mathrm{mg} / \mathrm{kg}$ were reported to have objective response. A 24-week progression-free survival (PFS) of $56 \%$ was reported in the RCC cohort, and five patients had responses lasting for 1 year and beyond.

McDermott et al published the long-term follow-up analysis (median of 45 months) of RCC patients enrolled in a second phase 1 trial. $^{27}$ The patients were treated up to 96 weeks or until they experienced disease progression, unacceptable adverse events, or CR. After 1 year of treatment, the patients showing objective response to treatment or having stable disease were observed and offered 1 additional year of nivolumab at progression. Radiologic response assessments were obtained after every 8-week treatment cycle. Treatment was continued beyond initial progression in patients without clinical evidence of disease progression until confirmation of progression in the next radiologic assessment. Responses were noted at both doses, 1 and $10 \mathrm{mg} / \mathrm{kg}$. The median time to tumor response was 16 weeks, whereas 4 of the 10 responding patients showed an objective response at the first radiographic assessment. The objective response rate for the entire group of RCC patients was $29.4 \%$ (95\% confidence interval [CI]: $15.1 \%-47.5 \%)$ with a median response duration of 12.9 months. The median PFS was 7.3 months (95\% CI: 3.6-10.9) and the median overall survival (OS) was 22.9 months (95\% CI: 12.5 to not estimable) for the entire cohort.

\section{Phase 2 clinical trial}

A randomized, blinded, multicenter, phase 2 clinical trial of nivolumab in $\mathrm{mRCC}$ was launched after the promising clinical activity in phase 1 studies. ${ }^{13}$ The study had three arms with 1:1:1 randomization to three different doses of nivolumab, $0.3,2$, and $10 \mathrm{mg} / \mathrm{kg}$. The randomization was stratified based on the number of prior therapies ( 1 versus $>1$ ) and MSKCC risk group (favorable or intermediate versus poor). The primary end point was PFS as a measure of dose-response relationship. The secondary end points were ORR, OS, and safety. One hundred and sixty-eight patients were enrolled in the study: 60 to receive nivolumab at $0.3 \mathrm{mg} / \mathrm{kg}$ and 54 each to receive nivolumab at 2 and $10 \mathrm{mg} / \mathrm{kg}$. The majority of patients $(70 \%)$ had received more than one therapy for mRCC and 42 patients (25\%) were categorized to have poor risk features by MSKCC criteria. Dose-response relationship was not observed for PFS, with a median PFS of 2.7 months (80\% CI: $1.9-3.0$ months), 4.0 months ( $80 \% \mathrm{CI}$ : 2.8-4.2 months), and 4.2 months (80\% CI: 2.8-5.5 months) for the $0.3,2$, and $10 \mathrm{mg} / \mathrm{kg}$ groups, respectively. Twelve patients in each of the 0.3 and $2 \mathrm{mg} / \mathrm{kg}$ arms and 11 patients in the $10 \mathrm{mg} / \mathrm{kg}$ arm were reported to have responded to nivolumab leading to an ORR of $20 \%, 22 \%$, and $20 \%$ in the $0.3,2$, and $10 \mathrm{mg} / \mathrm{kg}$ arms, respectively. Sustained response beyond 24 months was noted in 14 of the 35 (40\%) responders. Ten patients (17\%) in the $0.3 \mathrm{mg} / \mathrm{kg}$ group, $12(22 \%)$ in the $2 \mathrm{mg} / \mathrm{kg}$ group, and $14(26 \%)$ in the $10 \mathrm{mg} / \mathrm{kg}$ group were treated with nivolumab beyond radiographic progression. With a follow-up of at least 24 months, the study reported a median OS of 18.2 months (80\% CI: 16.2-24.0 months) in $0.3 \mathrm{mg} / \mathrm{kg}$ arm, 25.5 months (80\% CI: $19.8-28.8$ months) in the $2 \mathrm{mg} / \mathrm{kg}$ arm, and 24.7 months (80\% CI: 15.3-26.0 months) in the $10 \mathrm{mg} / \mathrm{kg}$ arm.

Overall, all the three arms had similar rates of adverse events. Fatigue was the most common adverse event reported. Nineteen patients developed grade 3 or 4 drug-related adverse effects, of which 4 of these patients were in the $0.3 \mathrm{mg} / \mathrm{kg}$ group, 14 were in the $1 \mathrm{mg} / \mathrm{kg}$ group, and 1 was in the $10 \mathrm{mg} / \mathrm{kg}$ group. No grade 3 or 4 pneumonitis was reported. Nausea, arthralgia, and elevation of alanine and arginine transaminases were the reported grade 3 to 4 adverse effects. In summary, this phase 2 clinical trial confirmed good activity of nivolumab in $\mathrm{mRCC}$, which was present across the three tested doses and all MSKCC risk groups.

\section{Phase 3 clinical trial}

Based on a successful phase 2 trial of nivolumab in $\mathrm{mRCC}$, a phase 3, multicenter, international, randomized study was performed ${ }^{28}$ (Table 1). Extrapolating from trials in melanoma and non-small-cell lung cancer, ${ }^{29-31}$ the $3 \mathrm{mg} / \mathrm{kg}$ nivolumab dose for every 2 weeks was selected. The aim of this study was to compare the efficacy of nivolumab with everolimus, an mTOR inhibitor, which was an approved second-line agent at the time for the management of $\mathrm{mRCC}$ after progression on an anti-VEGF agent. ${ }^{32}$ This was an 
Table I Clinical trials with nivolumab in metastatic RCC

\begin{tabular}{|c|c|c|c|c|}
\hline Clinical trial & Phase & $\begin{array}{l}\text { Number of subjects } \\
\text { with RCC }\end{array}$ & $\begin{array}{l}\text { Comparator } \\
\text { arm }\end{array}$ & Outcomes \\
\hline \multirow[t]{8}{*}{ Topalian et $\mathrm{al}^{24}$} & 1 & 34 & None & Dose: I mg/kg (n=17) \\
\hline & & & & ORR: $24 \%$ (95\% Cl: 7\%-50\%) \\
\hline & & & & SD $\geq 24$ weeks: $24 \%$ (95\% Cl: $7 \%-50 \%)$ \\
\hline & & & & mPFS at 24 weeks: $47 \%$ (95\% Cl: 23\%-7l\%) \\
\hline & & & & Dose: $10 \mathrm{mg} / \mathrm{kg}(\mathrm{n}=16)$ \\
\hline & & & & ORR: $31 \%$ (95\% Cl: $11 \%-59 \%)$ \\
\hline & & & & SD $\geq 24$ weeks: $31 \%$ (95\% Cl: II\%-59\%) \\
\hline & & & & mPFS at 24 weeks: $67 \%$ (95\% Cl: 43\%-91\%) \\
\hline \multirow[t]{12}{*}{ Motzer et al ${ }^{13}$} & 2 & 168 & None & Dose: $0.3 \mathrm{mg} / \mathrm{kg}(\mathrm{n}=60)$ \\
\hline & & & & ORR: $20 \%$ (80\% Cl: 13.4\%-28.2\%) \\
\hline & & & & mPFS: 2.7 months (80\% Cl: I.9-3.0) \\
\hline & & & & mOS: I8.2 months ( $80 \% \mathrm{Cl}:$ I6.2-24.0) \\
\hline & & & & Dose: I mg/kg $(\mathrm{n}=54)$ \\
\hline & & & & ORR: $22 \%$ (80\% Cl: $15.0 \%-31.1 \%)$ \\
\hline & & & & mPFS: 4 months (80\% Cl: $2.8-4.2)$ \\
\hline & & & & mOS: 25.5 months (80\% Cl: 19.8-28.8) \\
\hline & & & & Dose: $10 \mathrm{mg} / \mathrm{kg}(\mathrm{n}=54)$ \\
\hline & & & & ORR: $20 \%(80 \% \mathrm{Cl}: 13.4 \%-29.1 \%)$ \\
\hline & & & & mPFS: 4.2 months ( $80 \% \mathrm{Cl}: 2.8-5.5)$ \\
\hline & & & & mOS: 24.7 months (80\% Cl: I5.3-26.0) \\
\hline \multirow[t]{4}{*}{ Motzer et $\mathrm{a}^{28}$} & 3 & 821 & Everolimus & Dose: $3 \mathrm{mg} / \mathrm{kg}(\mathrm{n}=4 \mid 0)$ \\
\hline & & & & Odds ratio for response rate: 5.98 (95\% Cl: 3.68-9.72) \\
\hline & & & & mPFS: 4.6 months ( $95 \% \mathrm{Cl}: 3.7-5.4)$ \\
\hline & & & & mOS: 25.0 months ( $95 \% \mathrm{Cl}: 2 \mathrm{I} .8$ to NR) \\
\hline
\end{tabular}

Abbreviations: $\mathrm{Cl}$, confidence interval; mPFS, median progression-free survival; $\mathrm{mOS}$, median overall survival; $\mathrm{NR}$, not reached; ORR, objective response rate; RCC, renal cell carcinoma; SD, stable disease.

open-label study rather than blinded because of the differences in routes of administration (everolimus being oral and nivolumab being intravenous), scheduling (everolimus being daily and nivolumab being once every 2 weeks), dose modifications, and adverse event profiles. PFS had been the primary end point in several previous phase 3 trials of new agents, given the biology of mRCC. ${ }^{810,33}$ However, due to mechanism of action of nivolumab, enhancing inflammation around the tumor, there is a concern of radiologic evidence of progression, in the absence of true progression (which has been termed "pseudoprogression"); therefore, OS was chosen as the primary end point and not PFS. For the same reason, the trial also allowed for continuation of nivolumab beyond radiologic progression provided that the investigators saw clinical evidence of benefit. One hundred and forty-six study sites across 24 countries participated in this study, enrolling 821 patients: 410 in the nivolumab group and 411 in the everolimus group. ORR was higher in the nivolumab group compared to everolimus ( $25 \%$ versus 5\%, odds ratio, 5.98 [95\% CI: 3.68 to 9.72]; $P<0.001$ ). However, median PFS was not statistically different with 4.6 months (95\% CI: 3.7-5.4) in the nivolumab arm and 4.4 months (95\% CI: 3.7-5.5) in the everolimus arm. The median OS was significantly better in the nivolumab group at 25.0 months ( $95 \%$ CI: 21.8 to not estimable [NE]) compared to 19.6 months (95\% CI: 17.6-23.1) in the everolimus group. This benefit of nivolumab was seen across all the MSKCC risk groups. The adverse effects from nivolumab were on the expected lines (Table 2). Health-related quality of life measures (HRQoL) analysis was conducted among all patients who were randomized in this clinical trial, using Functional Assessment of Cancer Therapy-Kidney Symptom

Table 2 Major grade 3 or 4 adverse events noted in phase 3 clinical trial of nivolumab in RCC

\begin{tabular}{ll}
\hline Adverse events & Number (\%) of patients \\
\hline All events & $76(19)$ \\
Fatigue & $10(2)$ \\
Nausea & $1(<I)$ \\
Diarrhea & $5(1)$ \\
Decreased appetite & $2(<\mathrm{I})$ \\
Rash & $2(<\mathrm{I})$ \\
Anemia & $7(2)$ \\
Dyspnea & $3(1)$ \\
Pneumonitis & $6(1)$ \\
Hyperglycemia & $5(1)$ \\
\hline
\end{tabular}

Note: From N Engl J Med, Motzer RJ, Escudier B, McDermott DF, et al, Nivolumab versus everolimus in advanced renal-cell carcinoma, 373(19), 1803-1813, Copyright $\odot 2015$ Massachusetts Medical Society. Reprinted with permission from Massachusetts Medical Society. ${ }^{28}$

Abbreviation: RCC, renal cell carcinoma. 
Index-Disease-Related Symptoms (FKSI-DRS) and European Quality of Life (EuroQol)-5 Dimensions (EQ-5D) questionnaires. ${ }^{34}$ Two hundred of the 361 patients (55\%) in the nivolumab arm had clinically meaningful improvement in the FKSI-DRS score compared to 126 of the 343 patients $(37 \%)$ in the everolimus arm. This improvement in HRQoL should be considered with caution given the study was not blinded. In summary, the phase III trial showed clinically meaningful benefit from using nivolumab as a second-line treatment for advanced $\mathrm{mRCC}$.

\section{Regulatory approvals}

Based on the positive phase III clinical trial, the United States Food and Drug Administration on November 23, 2015, approved the use of nivolumab in the management of advanced mRCC after progression on first-line therapy. ${ }^{35}$ In a short time thereafter, the European Medicines Agency followed with its approval on February 26, 2016. ${ }^{36}$ In addition, nivolumab is currently approved for the management of unresectable or metastatic malignant melanoma as a single agent or in combination with ipilimumab, in metastatic non-small-cell lung cancer after progression on platinum-based chemotherapy regimen and in classical Hodgkin lymphoma that has relapsed or progressed after autologous hematopoietic stem cell transplantation. ${ }^{25}$ A dose of $3 \mathrm{mg} / \mathrm{kg}$ once every 2 weeks was approved across all indications, but recently, based on simulations by population pharmacokinetic models, the dose for mRCC, metastatic non-small-cell lung cancer, and melanoma (when used as a single agent) was changed to a fixed dose of $240 \mathrm{mg}$ once every 2 weeks. $^{37}$

\section{Predictive biomarker}

Even though it is clear that RCC responds to immunotherapy, the exact mechanism of action remains unclear. Melanoma and non-small-cell lung cancer have been shown to have high mutational burden leading to neoantigens; however, the neoantigen load in RCC is not very high. ${ }^{38-40}$ Evaluation of tumor samples from RCC patients has revealed that overexpression of PD-1 portends poor prognosis. ${ }^{41,42}$ Clinical trials have shown that $\sim 25 \%$ of patients with $\mathrm{mRCC}$ respond to PD-1 inhibitor nivolumab. PD-L1 expression has been tested as a potential biomarker in several studies involving nivolumab. In the phase 1 trial of nivolumab, the cell surface expression of PD-L1 was tested in 52 of the 256 patients, which included $5 \mathrm{mRCC}$ patients. ${ }^{24}$ Immunohistochemistry technique was used, and any degree of PD-L1 expression was considered positive. Twenty-five patients were reported to be positive for PD-L1 and 9 of them had objective response.
However, biopsy and PD-L1 staining were optional in this phase 1 study, and the biomarker analysis was not defined a priori; therefore, no major conclusions can be drawn.

In the phase 2 trial, PD-L1 expression was tested by using rabbit antihuman monoclonal antibody and a membranous staining of $>5 \%$ of cancer cells was reported as positive. ${ }^{13}$ Both fresh and archived tissues were obtained at enrollment and scoring was performed by two independent pathologists who were blinded. The PD-L1 expression was quantified in 107 of the 168 patients enrolled in the study. The results of the scoring were that $29(27 \%)$ of patients had PD-L1 expression $>5 \%$, whereas $78(73 \%)$ had $<5 \%$ expression. Both the overall response rate (ORR) and OS were higher in the group with $>5 \%$ of PD-L1 expression. The ORR was 31\% (95\% CI: $15.3-50.8)$ in the $>5 \%$ PD-L1 expression group compared to $18 \%(95 \% \mathrm{CI}: 10.2 \%-28.3 \%)$ in the $<5 \%$ group. The median OS was not reached $(95 \% \mathrm{CI}$ : 13.4 to not reached) in the $>5 \%$ PD-L1 expression group, whereas it was 18.2 months (95\% CI: 12.7-26.0) in the $<5 \%$ PD-L1 expression group. However, when a cutoff of $>1 \%$ PD-L1 expression was used, no significant differences were observed in ORR or OS.

The phase 3 trial of nivolumab in $\mathrm{mRCC}$ also tested PD-L1 expression as a potential biomarker. ${ }^{28}$ Tumor PD-L1 expression was quantifiable in $756(92 \%)$ patients out of the 821 enrolled in the study, which included $370(90 \%)$ in the nivolumab group and 386 (94\%) in the everolimus group. PD-L1 expression of $>1 \%$ was reported in 181 (24\%) of 756 patients and among them the median OS was 21.8 months (95\% CI: 16.5-28.1) in the nivolumab group compared to 18.8 months (95\% CI: 11.9-19.9) in the everolimus group. The remaining 575 patients had PD-L1 expression of $<1 \%$, and among them, the median OS was 27.4 months $(95 \%$ CI: 21.4 to not estimable) in the nivolumab group and 21.2 months (95\% CI: 17.7-26.2) in the everolimus group. The authors concluded that higher PD-L1 expression was associated with poor prognosis in $\mathrm{mRCC}$ patients and that PD-L1 expression can be used as an overall prognostic marker. However, PD-L1 expression did not predict response to nivolumab.

In summary, a predictive biomarker for response to nivolumab in $\mathrm{mRCC}$ patients remains elusive and further studies are warranted with alternative antibody stains for PD-L1 and staining tumor microenvironment in addition to just the tumor cells. ${ }^{43}$

\section{Management of toxicity and safety}

The adverse effects from nivolumab are unique compared to traditional chemotherapy agents and the TKIs. The 
common any grade side effects are fatigue, nausea, pruritus, and diarrhea. In the phase 3 clinical trial, 33\% of patients reported fatigue and $14 \%$ each reported nausea and pruritus. ${ }^{28}$ As nivolumab potentiates the immune system, it leads to a distinct set of autoimmune-mediated side effects. Pneumonitis, endocrinopathies (hypothyroidism and hypophysitis), and hepatitis are some of the potential autoimmune adverse effects. Case series with combination of nivolumab and ipilimumab have reported fatal complications including fulminant myocarditis. ${ }^{44}$ Systemic steroids are the cornerstone for treatment of these immune-mediated adverse effects. Grade 3 or 4 immune-related side effects warrant prompt discontinuation of the drug and treatment with $1 \mathrm{mg} / \mathrm{kg}$ prednisone or equivalent, with a slow taper over the course of a month after clinical or laboratory improvement.

\section{Combination therapy}

The combination of nivolumab and ipilimumab, a CTLA-4 antibody, in mRCC is being tested in first-line setting and at disease progression. ${ }^{45,46}$ This combination is approved for management of advanced melanoma. ${ }^{47}$ The phase 1 study of nivolumab plus ipilimumab (CheckMate-016) initially tested three different dosing schedules: nivolumab $1 \mathrm{mg} / \mathrm{kg}+$ ipilimumab 3 mg/kg (Nivo $1+$ Ipi 3), nivolumab $3 \mathrm{mg} / \mathrm{kg}+$ ipilimumab $1 \mathrm{mg} / \mathrm{kg}$ (Nivo 3 + Ipi 1), and nivolumab $3 \mathrm{mg} / \mathrm{kg}+$ ipilimumab $3 \mathrm{mg} / \mathrm{kg}$ (Nivo $3+$ Ipi 3). However, the accrual for Nivo 3 + Ipi 3 was stopped due to excessive toxicity, and the other two dosing schedules were recommended for expansion cohorts. Forty-seven patients were enrolled in the two arms. The majority of patients $(88 \%)$ had treatment-related side effects, as grade 3 or 4 adverse effects were noted in $34 \%$ of Nivo $3+$ Ipi 1 and $64 \%$ of Nivo $1+$ Ipi 3 treated patients. Gastrointestinal (colitis, diarrhea, and elevation of lipase) and hepatic (elevation of alanine transaminase and alkaline transaminase) were the most common reported grade 3 or 4 adverse events. The ORR and PFS rate at 24 weeks were $38.3 \%$ and $54 \%$, respectively, in the Nivo $3+$ Ipi 1 group, whereas they were $40.4 \%$ and $68 \%$, respectively, in the Nivo $1+$ Ipi 3 group. With this encouraging activity and safety profile, a phase 3 randomized clinical trial of Nivo $3+$ Ipi 1 versus sunitinib in newly diagnosed mRCC (CheckMate 214) was launched and the results of this trial are awaited. ${ }^{48}$

\section{Future directions}

Nivolumab is the first immune-checkpoint inhibitor to be approved for second-line therapy of $\mathrm{mRCC}$, after progression on VEGF-TKIs. Nivolumab has clearly shown benefit over everolimus; however, there are several other second-line options including axitinib and cabozantinib that have shown comparable PFS and OS benefits. It is important to point out that the side effect profile for nivolumab appears to be better than TKIs and about one-third of patients on phase 1 and phase 2 trials were alive at 5 and 3 years, respectively, suggesting a potential long-term benefit in selected patients. ${ }^{49}$ The sequencing of various VEGF-TKIs and nivolumab is still unclear and needs to be further elucidated in future clinical trials. There is preliminary evidence to suggest that nivolumab might be more efficacious in patients who progress on sunitinib than in patients who progress on pazopanib. ${ }^{50,51}$ The safety profile of nivolumab is clearly established, and long-term use has been evaluated in various malignancies including mRCC. Clinical trials testing the combination therapy of nivolumab plus VEGF-TKIs or nivolumab and other immune-modulating agents are underway, which will shed more light into its use in $\mathrm{mRCC}$, including the possible utility in front-line setting (Table 3). Other possible settings for use of nivolumab include neoadjuvant and adjuvant setting in high-risk non-mRCC patients. Over the next few years, other anti-PD-1 and anti-PD-L1 agents may be approved for mRCC including pembrolizumab, avelumab, and atezolizumab, which would add to the therapeutic repertoire. In addition, further research is needed for developing predictive biomarkers to identify patients who would benefit most from the PD-1-directed therapy. No single PD-L1 biomarker stain has been standardized. In the future, a combination of various biomarkers like PD-L1 staining, immune microenvironment surrounding the tumor, and mutation burden might prove to be a better marker for response to anti-PD-1/PD-L1 therapy.

Table 3 Ongoing clinical trials with nivolumab in RCC

\begin{tabular}{lllll}
\hline Clinical trial & Phase & Number of patients & Intervention & Setting \\
\hline NCT02575222 & $\mathrm{I}$ & 30 & Nivolumab as a single agent & Neoadjuvant in high-risk patients \\
NCT025959I8 & $\mathrm{I}$ & 29 & Nivolumab & Neoadjuvant in high-risk patients \\
NCT02899078 & $\mathrm{Ib} / 2$ & 30 & Nivolumab and ibrutinib & Previously treated metastatic RCC \\
NCT027I8066 & $\mathrm{Ib} / 2$ & 78 & Nivolumab and HBI-8000 & Advanced RCC \\
NCT0292353I & $\mathrm{Ib} / 2$ & 20 & Nivolumab and XP4-00I & Metastatic clear cell RCC \\
NCT0278I506 & 2 & 35 & Nivolumab and stereotactic ablative radiation therapy & MCC and other malignancies \\
\hline
\end{tabular}

Abbreviation: RCC, renal cell carcinoma. 
Finally, the role of anti-PD-1/PD-L1 therapy in non-clear cell RCC needs further investigation.

\section{Disclosure}

The authors report no conflicts of interest in this work.

\section{References}

1. Miller KD, Siegel RL, Lin CC, et al. Cancer treatment and survivorship statistics, 2016. CA Cancer J Clin. 2016;66(4):271-289.

2. Linehan WM, Walther MM, Zbar B. The genetic basis of cancer of the kidney. J Urol. 2003;170(6 Pt 1):2163-2172.

3. Stephenson AJ, Chetner MP, Rourke K, et al. Guidelines for the surveillance of localized renal cell carcinoma based on the patterns of relapse after nephrectomy. J Urol. 2004;172(1):58-62.

4. Sandock DS, Seftel AD, Resnick MI. A new protocol for the followup of renal cell carcinoma based on pathological stage. J Urol. 1995;154(1):28-31.

5. Flanigan RC, Salmon SE, Blumenstein BA, et al. Nephrectomy followed by interferon alfa- $2 \mathrm{~b}$ compared with interferon alfa- $2 \mathrm{~b}$ alone for metastatic renal-cell cancer. $N$ Engl J Med. 2001;345(23):1655-1659.

6. Molina AM, Motzer RJ, Heng DY. Systemic treatment options for untreated patients with metastatic clear cell renal cancer. Semin Oncol. 2013;40(4):436-443

7. McDermott DF. Immunotherapy of metastatic renal cell carcinoma. Cancer. 2009;115(10 Suppl):2298-2305.

8. Motzer RJ, Hutson TE, Tomczak P, et al. Sunitinib versus interferon alfa in metastatic renal-cell carcinoma. $N$ Engl J Med. 2007;356(2): $115-124$.

9. Escudier B, Eisen T, Stadler WM, et al. Sorafenib in advanced clear-cell renal-cell carcinoma. $N$ Engl J Med. 2007;356(2):125-134.

10. Rini BI, Escudier B, Tomczak P, et al. Comparative effectiveness of axitinib versus sorafenib in advanced renal cell carcinoma (AXIS): a randomised phase 3 trial. Lancet. 2011;378(9807):1931-1939.

11. Motzer RJ, Hutson TE, Cella D, et al. Pazopanib versus sunitinib in metastatic renal-cell carcinoma. $N$ Engl J Med. 2013;369(8):722-731.

12. Escudier B, Pluzanska A, Koralewski P, et al. Bevacizumab plus interferon alfa-2a for treatment of metastatic renal cell carcinoma: a randomised, double-blind phase III trial. Lancet. 2007;370(9605): 2103-2111.

13. Motzer RJ, Hutson TE, Glen H, et al. Lenvatinib, everolimus, and the combination in patients with metastatic renal cell carcinoma: a randomised, phase 2, open-label, multicentre trial. Lancet Oncol. 2015; 16(15):1473-1482.

14. Janiszewska AD, Poletajew S, Wasiutynski A. Spontaneous regression of renal cell carcinoma. Contemp Oncol (Pozn). 2013;17(2):123-127.

15. Melichar B, Vaneckova J, Moravek P, et al. Spontaneous regression of renal cell carcinoma lung metastases in a patient with psoriasis. Acta Oncol. 2009;48(6):925-927.

16. Beckermann KE, Johnson DB, Sosman JA. PD-1/PD-L1 blockade in renal cell cancer. Expert Rev Clin Immunol. 2016;13(1):1-8.

17. Melero I, Hervas-Stubbs S, Glennie M, et al. Immunostimulatory monoclonal antibodies for cancer therapy. Nat Rev Cancer. 2007;7(2): 95-106.

18. Mellman I, Coukos G, Dranoff G. Cancer immunotherapy comes of age. Nature. 2011;480(7378):480-489.

19. Hirano F, Kaneko K, Tamura H, et al. Blockade of B7-H1 and PD-1 by monoclonal antibodies potentiates cancer therapeutic immunity. Cancer Res. 2005;65(3):1089-1096.

20. Iwai Y, Okazaki T, Nishimura H, et al. Microanatomical localization of PD-1 in human tonsils. Immunol Lett. 2002;83(3):215-220.

21. Schalper KA. Programmed death-1/programmed death-1 ligand axis as a therapeutic target in oncology: current insights. J Receptor Ligand Channel Res. 2015;8:1-7.

22. Francisco LM, Sage PT, Sharpe AH. The PD-1 pathway in tolerance and autoimmunity. Immunol Rev. 2010;236:219-242.
23. Nishimura H, Nose M, Hiai H, et al. Development of lupus-like autoimmune diseases by disruption of the PD-1 gene encoding an ITIM motif-carrying immunoreceptor. Immunity. 1999;11(2):141-151.

24. Topalian SL, Hodi FS, Brahmer JR, et al. Safety, activity, and immune correlates of anti-PD-1 antibody in cancer. $N$ Engl J Med. 2012; 366(26):2443-2454.

25. Nivolumab (Opdivo) [package insert]. Princeton, NJ: Bristol-Myers Squibb; 2016.

26. Brahmer JR, Drake CG, Wollner I, et al. Phase I study of single-agent anti-programmed death-1 (MDX-1106) in refractory solid tumors: safety, clinical activity, pharmacodynamics, and immunologic correlates. J Clin Oncol. 2010;28(19):3167-3175.

27. McDermott DF, Drake CG, Sznol M, et al. Survival, durable response, and long-term safety in patients with previously treated advanced renal cell carcinoma receiving nivolumab. J Clin Oncol. 2015;33(18): 2013-2020.

28. Motzer RJ, Escudier B, McDermott DF, et al. Nivolumab versus everolimus in advanced renal-cell carcinoma. N Engl J Med. 2015;373(19): $1803-1813$.

29. Robert C, Long GV, Brady B, et al. Nivolumab in previously untreated melanoma without BRAF mutation. $N$ Engl J Med. 2015;372(4): 320-330.

30. Borghaei H, Paz-Ares L, Horn L, et al. Nivolumab versus docetaxel in advanced nonsquamous non-small-cell lung cancer. $N$ Engl J Med. 2015;373(17):1627-1639.

31. Brahmer J, Reckamp KL, Baas P, et al. Nivolumab versus docetaxel in advanced squamous-cell non-small-cell lung cancer. $N$ Engl $J$ Med. 2015;373(2):123-135.

32. Motzer RJ, Escudier B, Oudard S, et al. Efficacy of everolimus in advanced renal cell carcinoma: a double-blind, randomised, placebocontrolled phase III trial. Lancet. 2008;372(9637):449-456.

33. Sternberg CN, Davis ID, Mardiak J, et al. Pazopanib in locally advanced or metastatic renal cell carcinoma: results of a randomized phase III trial. J Clin Oncol. 2010;28(6):1061-1068.

34. Cella D, Grunwald V, Nathan P, et al. Quality of life in patients with advanced renal cell carcinoma given nivolumab versus everolimus in CheckMate 025: a randomised, open-label, phase 3 trial. Lancet Oncol. 2016;17(7):994-1003.

35. FDA approves Opdivo to treat advanced form of kidney cancer. Available from: http://www.fda.gov/NewsEvents/Newsroom/ PressAnnouncements/ucm473971.htm. Accessed November 11, 2016.

36. New treatment for advanced form of kidney cancer. Available from: http:// www.ema.europa.eu/ema/index.jsp?curl=pages/news_and_events/ news/2016/02/news_detail_002478.jsp\&mid=WC0b01ac058004d5c1. Accessed November 11, 2016.

37. Modification of the dosage regimen for nivolumab: FDA; 2016. Available from: http://www.fda.gov/Drugs/InformationOnDrugs/ApprovedDrugs/ucm520871.htm. Accessed November 25, 2016.

38. Lawrence MS, Stojanov P, Polak P, et al. Mutational heterogeneity in cancer and the search for new cancer-associated genes. Nature. 2013; 499(7457):214-218

39. Rizvi NA, Hellmann MD, Snyder A, et al. Cancer immunology. Mutational landscape determines sensitivity to PD-1 blockade in non-small cell lung cancer. Science. 2015;348(6230):124-128.

40. Snyder A, Makarov V, Merghoub T, et al. Genetic basis for clinical response to CTLA-4 blockade in melanoma. NEnglJMedi.2014;371(23): 2189-2199.

41. Thompson RH, Dong H, Lohse CM, et al. PD-1 is expressed by tumor-infiltrating immune cells and is associated with poor outcome for patients with renal cell carcinoma. Clin Cancer Res. 2007;13(6): $1757-1761$.

42. Thompson RH, Dong H, Kwon ED. Implications of B7-H1 expression in clear cell carcinoma of the kidney for prognostication and therapy. Clin Cancer Res. 2007;13(2 Pt 2):709s-715s.

43. Ornstein MC, Rini BI. The safety and efficacy of nivolumab for the treatment of advanced renal cell carcinoma. Expert Rev Anticancer ther. 2016; 16(6):577-584. 
44. Johnson DB, Balko JM, Compton ML, et al. Fulminant myocarditis with combination immune checkpoint blockade. N Engl J Med. 2016; 375(18):1749-1755.

45. Hammers H, Elizabeth P, Infante J, et al. Expanded cohort results from CheckMate 016: a phase I study of nivolumab in combination with ipilimumab in metastatic renal cell carcinoma (mRCC). ASCO Annual Meeting; Chicago. J Clin Oncol. 2015;33.

46. Hammers H, Plimack ER, Infante JR, et al. 1050OPhase I study of nivolumab in combination with ipilimumab in metastatic renal cell carcinoma (MRCC). Ann Oncol. 2014;25(Suppl 4):iv361-iv362.

47. Postow MA, Chesney J, Pavlick AC, et al. Nivolumab and ipilimumab versus ipilimumab in untreated melanoma. N Engl J Med. 2015;372(21): 2006-2017.
48. Nivolumab combined with ipilimumab versus sunitinib in previously untreated advanced or metastatic renal cell carcinoma (CheckMate 214). Available from: https://clinicaltrials.gov/ct2/show/NCT02231749. Accessed November 25, 2016.

49. McDermott DF, Motzer RJ, Atkins MB, et al. Long-term overall survival (OS) with nivolumab in previously treated patients with advanced renal cell carcinoma (aRCC) from phase I and II studies. Annual Meeting of the American Society of Clinical Oncology, Abstract 4507; Chicago: Journal of Clinical Oncology. 2016.

50. Huillard O, Alexandre J, Goldwasser F. Treatment of advanced renalcell carcinoma. $N$ Engl J Med. 2016;374(9):888.

51. Motzer RJ, Escudier B, Choueiri TK. Treatment of advanced renal-cell carcinoma. N Engl J Med. 2016;374(9):889-890.

\section{Publish your work in this journal}

Drug Design, Development and Therapy is an international, peerreviewed open-access journal that spans the spectrum of drug design and development through to clinical applications. Clinical outcomes, patient safety, and programs for the development and effective, safe, and sustained use of medicines are the features of the journal, which has also been accepted for indexing on PubMed Central. The manuscript management system is completely online and includes a very quick and fair peer-review system, which is all easy to use. Visit http://www.dovepress.com/testimonials.php to read real quotes from published authors.

Submit your manuscript here: http://www.dovepress.com/drug-design-development-and-therapy-journal 